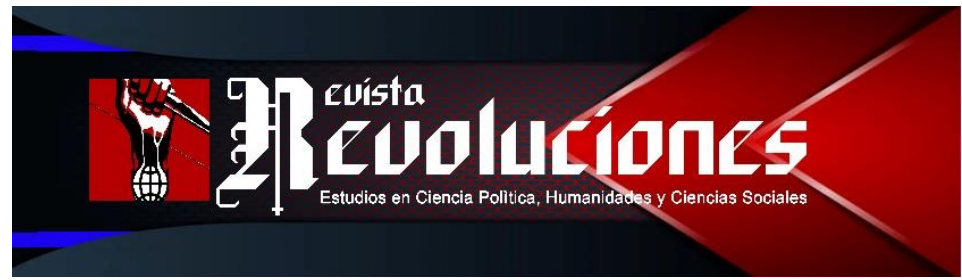

\title{
REPRESENTACIONES SOCIALES DE LOS ACTORES POLÍTICOS SOBRE LA GESTIÓN DE LAS ORGANIZACIONES POLÍTICAS REGIONALES
}

\section{Social representations of political actors on the management of regional political organizations}

\author{
Gustavo Medina Vilca ${ }^{1}$ \\ UNIVERSIDAD NACIONAL DEL \\ ALTIPLANO \\ PERÚ \\ g.medina@unap.edu.pe \\ https://orcid.org/o000-0001- \\ 5159-1195
}

\author{
Rogelio Morales ${ }^{2}$ \\ UNIVERSIDAD NACIONAL DEL \\ ALTIPLANO \\ PERÚ \\ moralesrmt@gmail.com \\ https://orcid.org/o00o-0003- \\ 1229-3640
}

\begin{abstract}
DOI: https://doi.org/10.35622/j.rr.2019.01.004
Recibido: 05-I-2019 / Aceptado: 28-I-2019 / Actualizado: 14-VIII-2020
\end{abstract}

\section{Resumen}

El propósito de esta investigación fue analizar las representaciones sociales de los actores políticos sobre la gestión de las organizaciones políticas regionales en la Región Puno, Perú. El enfoque que se utilizó en la investigación es el cualitativo, cuyo diseño es descriptivo comprensivo porque describe los conocimientos, identifica las actitudes y expectativas que tienen los actores políticos sobre la gestión de las organizaciones políticas regionales, y, es comprensivo porque se interpreta las actitudes y expectativas de los actores políticos. El objetivo planteado fue analizar las representaciones sociales que tienen los actores políticos sobre la gestión de las organizaciones políticas regionales. Los resultados indican que en las organizaciones políticas se adoptan actitudes positivas sobre la ideología, pasivas sobre los líderes y militantes, y cuentan con expectativas favorables para la participación en los procesos electorales.

Palabras Clave: Actores políticos, gestión política, organizaciones políticas, representaciones sociales.

\begin{abstract}
The purpose of this research was to analyze the social representations of political actors on the management of regional political organizations in Puno region, Perú. The approach that

\footnotetext{
${ }^{1}$ Sociólogo con conocimientos y habilidades en gerencia de instituciones, organizaciones y empresas. Con experiencia en gestión pública y docencia universitaria de pre grado y posgrado en la Universidad Nacional del Altiplano.
}

${ }^{2}$ Licenciado en Sociología por la Universidad Nacional del Altiplano.
\end{abstract}


was used in the investigation is the qualitative one, whose design is descriptive comprehensive because it describes the knowledge, it identifies the attitudes and expectations that the political actors have on the management of the regional political organizations, and, it is comprehensive because there are interpreted the attitudes and expectations of the political actors. The raised target was to analyze the social representations that the political actors have on the management of the regional political organizations. The results indicate that political organizations positive attitudes about ideology, passive on the leaders and militants, and have favorable expectations for participation in electoral processes are adopted.

Keyword: Political actors, political management, political organizations, social representations.

\section{INTRODUCCIÓN}

En América Latina a partir de la década de los ochenta se ha iniciado un periodo de tránsito y afinidad a la democracia, en ese contexto los partidos políticos asumieron el rol protagónico para constituirse en el soporte del sistema democrático. En el Perú, en paralelo al contexto internacional a lo largo de nuestra vida republicana, se han turnado 93 gobiernos, 55 han llegado a gobernar por autoproclamación, golpe de estado y encargo provisional y sólo 28 por elección de ciudadanía y 10 por elección del congreso. El primer grupo encarna a los gobiernos autoritarios y los últimos figuran el sistema democrático (Arriaga, 2003). Con el retorno a la democracia en la década de los ochenta y después de 12 años de ejercicio democrático llegamos a ante una nueva situación de transición democrática frustrada, "debido a la debilidad de la oposición y la escasa competencia en el sistema político" (Tanaka, 1999, p. 14).

En ese contexto, el panorama político regional, según el portal virtual del Jurado Nacional de Elecciones en la ventana del Infogob revela los índices de participación electoral, en el componente ciudadano se caracteriza por la escasa cantidad de electores afiliados a las organizaciones políticas.

$\mathrm{El}$ abordar las representaciones sociales encuentra su fundamento en los hechos sociales que se conciben como: "Todos los fenómenos que se desarrollan en el interior de la sociedad, siempre que presenten, con cierta generalización, algún interés social” (Durkheim, 1997, p. 39). Estos fenómenos o hechos sociales "Consisten en modos de actuar, de pensar y de sentir, exteriores al individuo, y están dotados de un poder de coacción en virtud del cual se imponen sobre él” (Durkheim, 1997, p. 41).

Desde otro enfoque, tenemos que, "las representaciones sociales se presentan bajo formas variadas, más o menos complejas. Imágenes que condensan un conjunto de significados; sistemas de referencia que nos permiten interpretar lo que nos sucede, e incluso dar un sentido a lo inesperado; categorías que sirven para clasificar las circunstancias, los 
fenómenos y los individuos con quienes tenemos algo que ver; teorías que nos permiten establecer hechos sobre ellos. Y a menudo cuando se les comprende dentro de la realidad concreta de la vida social, las representaciones sociales son todo ello junto" (Jodelet, 1986, p. 472).

$\mathrm{Al}$ analizar la democracia, el sistema de partidos y el sistema electoral concebimos que existen diferentes tipificaciones sobre lo que es democracia directa o participativa ejercida directamente por los ciudadanos a través de la iniciativa popular, referéndum o plebiscito y la revocación de cargos electos y la democracia Indirecta o Representativa; se delega el ejercicio democrático a representantes electos que son autoridades. Y un tercero poco conocido pero estipulado en la Constitución Política del Estado Plurinacional de Bolivia como la democracia comunitaria.

El "partido político, es la primera célula en que se agrupan gérmenes de voluntad colectiva que tienden a hacerse universales y totales" (Gramsci, 1981, p. 15). El partido también pude se concebido como "una comunidad de una estructura particular, caracterizada principalmente por las relaciones internas entre los miembros de la comunidad" (Duverger, 1987, p. 34), o un "grupo político identificado por una etiqueta oficial que presenta a las elecciones, y es puede sacar en elecciones (libres o no) candidatos a cargos públicos" (Sartori, 1992, p. 89).

Respecto a la gestión organizacional de partidos u organizaciones políticas, consideramos que el partido político como organización, como sistema social tiene sus procesos de interacción, su dinámica de funcionamiento, posee normas y procedimientos. Desde esa perspectiva "las organizaciones partidistas no son actores unitarios sino complejas organizaciones que se comportan en ámbitos diversos y con una variopinta gama de intereses, por lo que dentro de ellos compiten intereses particulares en función muchas veces de motivaciones individuales" (Meléndez, 2002, p. 37).

La organización interna de los partidos se refiere, entonces, a las "estructuras y reglas que regulan la interacción entre los distintos actores que los componen, el ámbito externo de la organización partidista se refiere al vínculo entre los partidos y su entorno y al papel y actividades desempeñadas por determinados actores y organismos del partido en los ámbitos en los que éstos actúan" (Meléndez, 2002, p. 38).

En este sentido, las organizaciones políticas en tanto gestión interna deberán dedicarse a la más adecuada estructuración, definición de reglas factibles que permita organizar actividades, gestionar los miembros o afiliados, tomar decisiones, generar propuestas políticas y estrategias electorales exitosas. En tanto, la gestión externa está en relación con el entorno que los actores políticos y la misma organización mantiene.

\section{METODOLOGÍA}


Por la naturaleza del trabajo de investigación que se propuso analizar las representaciones sociales de los actores políticos sobre la gestión organizacional de sus organizaciones políticas regionales a partir de la construcción subjetiva de los actores involucrados, por tanto el método más conveniente fue el hermenéutico comprensivo y para el análisis de los mismos el método dialectico crítico; asimismo, la investigación se enmarca en el enfoque cualitativo, por su nivel de profundidad es de tipo descriptivo - comprensivo. Los ejes de análisis son los conocimientos, las actitudes y las expectativas de los actores políticos sobre la gestión de las organizaciones políticas regionales.

Para la selección de las organizaciones políticas regionales se ha tomado criterios como: inscripción vigente en el registro de organizaciones políticas (ROP), participación en procesos electorales anteriores, acceso al poder (gobierno regional y municipios provinciales ganados en el último proceso electoral) y mayor estructuración organizativa regional, para la selección de los informantes claves se ha tomado los que asumen o han asumido cargos como personero legal, de dirigencia, ex o potenciales candidatos a presidente o consejo regional, autoridades electas y líderes con trayectoria política que pertenezcan a la organización política regional. Se asumió una muestra intencionada de tres informantes claves por organización política regional. La entrevista a profundidad y la guía de entrevista ha sido el instrumento que se utilizó para el recojo de la información, y la información ha sido procesada y analizada con uso del software para análisis de datos cualitativos ATLAS.ti7.

\section{RESULTADOS Y DISCUSIÓN}

\section{Conocimientos de los actores políticos sobre la organización interna de las organizaciones políticas regionales}

\section{Estructura, cargos y funciones}

Por lo general, las organizaciones políticas tienen una estructura organizativa de carácter vertical, jerarquizado y bajo la estructura político territorial. En las organizaciones políticas regionales el nivel máximo de la estructura organizativa es la instancia regional, provincial y distrital, y que éstas dos últimas son la base de la estructura organizativa que mantiene una vinculación directa con la sociedad.

Los actores políticos conocen con más amplitud la estructura funcional, son quienes ejercen o han ejercido cargos de personero legal y dirigencias porque son quienes toman las decisiones en primera instancia, representan a la organización política y coordinan con las demás instancias de gobierno. Así mismo, los líderes políticos y candidatos conocen de manera aceptable ya que son los más visibles para la población. Finalmente, quienes conocen de manera más superficial son los que desempeñan cargos públicos que han sido elegidos por las organizaciones políticas al que pertenecen porque las actividades propias del ejercicio de sus funciones limitan su participación activa en la organización política. 
Como se muestra en la Figura $\mathrm{N}^{\circ}$ 01, en relación a la estructura funcional en su organización política, los actores políticos de los movimientos regionales Poder Democrático Regional (PDR), Frente Amplio para el Desarrollo del Pueblo (FADEP), Proyecto de la Integración para la Cooperación PICO y el movimiento regional Por Las Comunidades Fuente de Integración Andina de Puno (CONFIA) expresan que funcionan en base al comité ejecutivo regional, comité ejecutivo provincial y comité ejecutivo distrital y que éstos constituyen órganos deliberativos y de representación a nivel regional, provincial y distrital. Además, un aspecto importante es subrayar con referencia a los del PDR que manifestaron la existencia de un comité político regional como parte de la estructura funcional regional de su organización política, pero, con carácter más permanente y los del FADEP no hacen referencia a la estructura de nivel distrital.

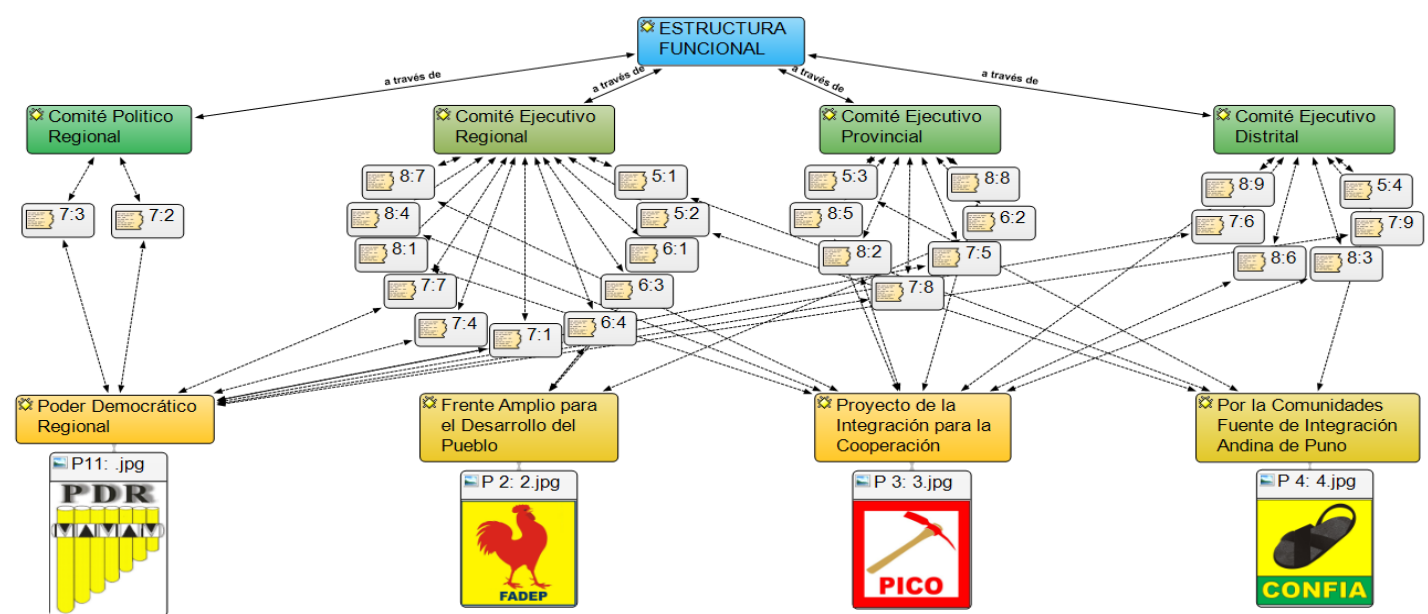

Figura 1: Red hermenéutica de conocimientos sobre la estructura funcional de las organizaciones políticas regionales (ATLAS.ti7).

Respecto a los cargos de las organizaciones políticas, podemos decir que son determinados por los miembros mediante una elección directa o delegados. Lo importante es destacar que por este medio se delega la autoridad a los representantes de la organización política, por lo que la participación de los miembros es importante, ya que "el uso de mecanismos más participativos e incluyentes en la elección de autoridades, junto a una alta renovación de las élites, contribuyen con mayores cotas de democracia interna en la organización" (Freindenberg, 2006, p. 102).

Respecto a las funciones, éstas son una serie de actividades realizadas por los titulares de los cargos de la organización política en servicio de sus miembros y la organización misma. Así tenemos los siguientes testimonios:

"El principal cargo es la secretaria general...aparte de eso tenemos el comité regional que está conformado como vuelvo a repetir de los 13 secretarios regionales más los 11 miembros que son elegidos en asamblea... tienen la función de representar políticamente y tener la voz pública del PDR y ser los portavoces de las decisiones que tomen las instancias colectivas" (Líder político, PDR). 
"El principal cargo, es la presidencia que delinean y construyen los lineamientos del partido (...) las demás secretarias que tenemos como de juventud, de la mujer, de organizaciones sociales, de economía como en toda organización se procura cumplir con los fines y objetivos del movimiento" (Dirigente, FADEP).

Por tanto, la principal función la asumen el secretario general regional y el presidente orientando la política, representando, tomando decisiones y haciendo cumplir acuerdos; las funciones de las secretarías ejecutivas del comité regional es direccionar y ejecutar los acuerdos de su sector, y finalmente, el secretario general provincial y distrital cumplen las funciones de direccionar y coordinar el funcionamiento de la organización política en el nivel de representación que tienen.

\section{Democracia interna}

La democracia interna, es concebida como "un concepto multidimensional, empleado de manera cotidiana y caracterizada por su utilización normativa, puesto que se le suele asociar con la idea de lo que debería ser un buen partido más que con lo que describe el comportamiento partidista" (Freidenberg, 2005, p. 93).

Así mismo, "la democracia interna en un partido supone la adopción de principios de este sistema político al interior de la organización" (Freidenberg, 2006, p. 3). Estos valores están estrictamente relacionados a la promoción de la igualdad, participación colectiva y el control de los representantes.

En cuanto a la definición e importancia de la democracia interna (Figura $\mathrm{N}^{\circ}$ o2), es el candidato y algunos dirigentes y personeros legales conocen también sobre la importancia de la democracia interna en la organización política porque son quienes aplican o han sido elegidos por este mecanismo.

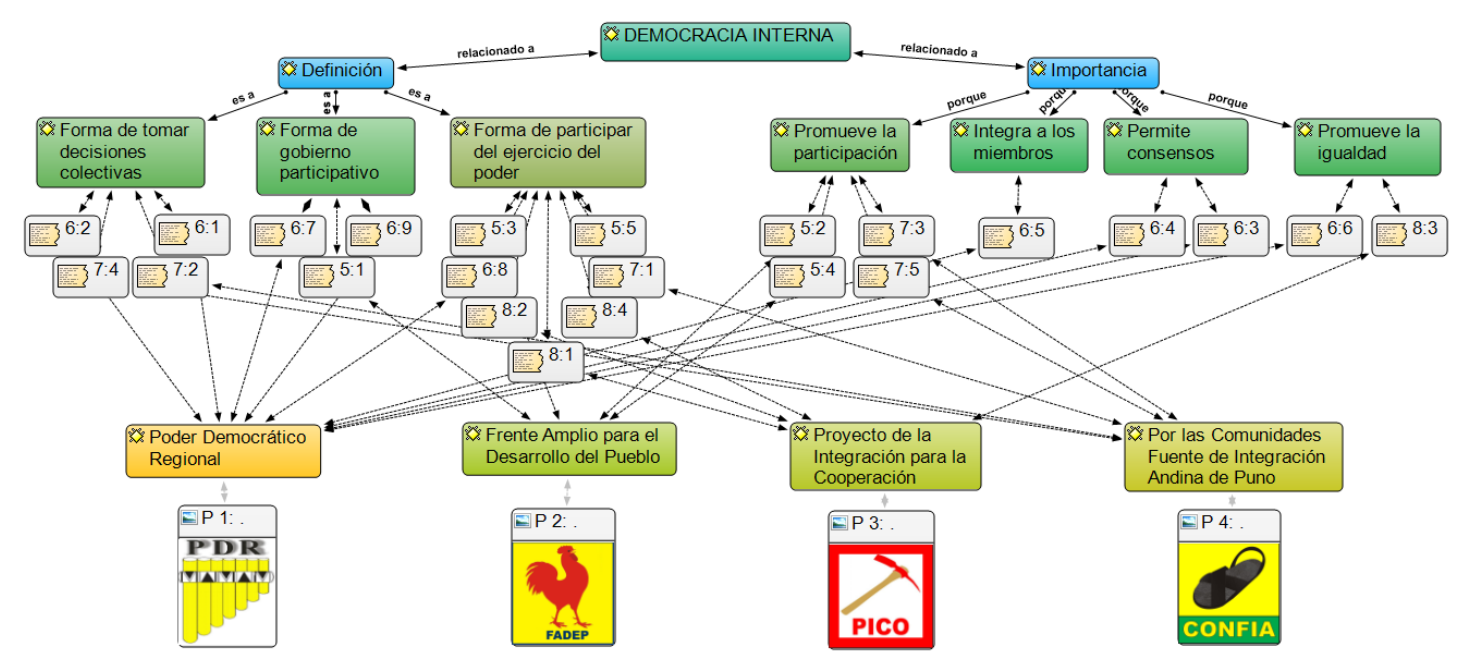

Figura 2. Red hermenéutica de conocimientos sobre la democracia interna de las organizaciones políticas regionales (ATLAS.ti7). 
De los discursos podemos afirmar que la democracia interna es una forma de participación en el ejercicio del poder, es gobierno participativo, es tomar decisiones colectivas; y es importante porque se promueve la participación e igualdad, se permite consensos y la integración de los miembros. Por tanto, son conocimientos suficientes de los actores políticos sobre la democracia interna en las organizaciones políticas regionales.

Por eso, se dice que "un partido gozará de democracia interna cuando sus líderes y candidatos sean elegidos por los miembros, a través de mecanismos competitivos; donde las decisiones sean inclusivas y se tomen con la participación voluntaria de sus integrantes; los órganos de gobierno no discrimine la integración de los diferentes grupos, y se respete una serie de derechos y responsabilidades, protegiendo incluso a aquellos que opinan y se manifiestan de manera distinta a la coalición dominante" (Freidenberg, 2005, p. 95).

Desde los testimonios tenesmos que:

"Esta democracia interna se refleja de manera muy visible en la elección de los representantes del movimiento, las candidaturas es un tema sensible y en un momento electoral de mucho movimiento a veces se hace complicado su cumplimiento". (Personero legal, CONFIA).

"Se aplica generalmente en la elección de cargos para dirigentes y las candidaturas, no se aplica o mejor dicho no se aplica de manera efectiva o falta mejorar, en las decisiones... muchas de las decisiones se toman a nivel del grupo de dirigentes que si están reunidos permanentemente" (Personero legal, CONFIA).

"Básicamente, se utiliza la democracia interna para aspectos como la elección de sus dirigentes ya sea distritales, provinciales, regionales" (Autoridad, FADEP).

"Aplicamos la democracia interna como práctica institucionalizada en las decisiones de asamblea, la elección de nuestros dirigentes y candidatos; pero nos falta reforzar la democracia interna en la elección de candidatos". (Autoridad, PICO).

En cuanto a la práctica de la democracia interna, los dirigentes, líderes, personeros legales, autoridades y candidatos conocen sobre la práctica de la democracia interna; sin embargo, para algunos dirigentes, autoridades y personeros legales dicha práctica de la democracia interna es algo que no se ha estado aplicando correctamente en la elección de los candidatos lo que constituye una debilidad en las organizaciones políticas regionales. Asimismo, podemos afirmar que las organizaciones políticas regionales practican plenamente la democracia interna, en la elección de dirigentes; se practica menos y con debilidades en la elección de candidatos; y así mismo, en la toma de decisiones se practica con cierta regularidad.

\section{Documentos de gestión interna}

La organización interna de los partidos se refiere, entonces, a las estructuras y reglas que regulan la interacción entre los distintos actores que los componen (Meléndez, 2002, p. 38). En este caso, los documentos de gestión interna que regulan la interacción en la organización 
política regional son el estatuto y reglamentos internos. Al respecto tenemos los siguientes testimonios:

"Nosotros tenemos el estatuto y la filosofía del movimiento que es el documento básico" (Dirigente, PICO).

"Esta el estatuto que es el documento básico que rige a toda la organización que además es oficialmente reconocido por el JNE" (Personero legal, CONFIA).

"Tenemos el estatuto de la organización, inscrito en los registros públicos...Para cada congreso hacemos un reglamento interno... y de elecciones y luego tenemos nuestro ideario... Para cada elección hemos ido construyendo todo un expediente del programa del partido para gobernar la región y las provincias" (Ex dirigente PDR).

En cuanto a los aspectos relevantes del estatuto y reglamentos internos, los actores políticos en general conocen los contenidos del estatuto; sin embargo, todos estos actores políticos no mencionan sobre los aspectos relevantes de los reglamentos internos ya que hay un desconocimiento al respecto o la organización política no cuenta con ellos. Como se muestra en la Figura $\mathrm{N}^{\circ} \mathrm{O}$, los aspectos relevantes del estatuto de la organización política.

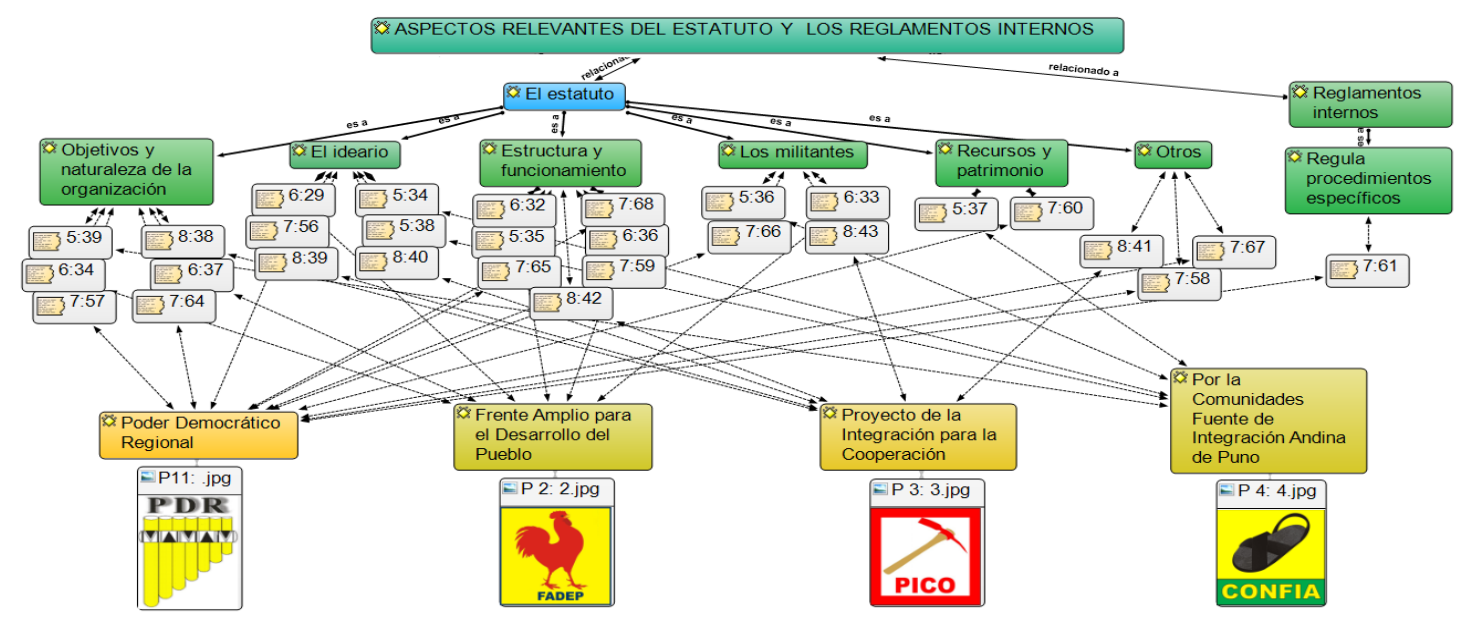

Figura 3. Red hermenéutica de conocimientos sobre los aspectos relevantes del estatuto y los reglamentos internos de las organizaciones políticas regionales (ATLAS.ti7).

En relación a los aspectos relevantes del estatuto de la organización política, los actores políticos del PDR, FADEP, PICO y CONFIA expresan que el estatuto es un documento de gestión interna, que contiene aspectos relevantes como son: la estructura y funcionamiento, los objetivos y naturaleza, el ideario y los militantes de la organización política. El PDR y CONFIA hacen referencia a los recursos y patrimonio de la organización política y otros aspectos relevantes; en relación al reglamento interno de la organización política, los del PDR hacen referencia, el mismo que contiene disposiciones que regula procedimientos para eventos o situaciones específicas. Por tanto, los conocimientos que se tienen los actores políticos son suficientes sobre los aspectos relevantes del estatuto y deficientes sobre los reglamentos internos de las organizaciones políticas regionales, ya que estos deben contener procedimientos para eventos o situaciones propias de la organización. 


\section{Actitudes de los actores políticos sobre la formación ideológica de líderes y la captación de militantes de las organizaciones políticas regionales}

\section{Ideología}

La ideología se ha conceptualizado como un conjunto de ideas y valores que una función de guiar el comportamiento político de los partidarios. La práctica política muestra comportamientos colectivos guiados por una constante tensión dada por los valores de igualdad y libertad ya que los más cercanos al valor de la igualdad son los partidos de izquierda, mientras que los partidos de derecha se les ubican más cercanos a la libertad, por lo que la orientación política se divide de forma clásica en posiciones de izquierda y de derecha. "La variable más explicativa de situaciones de democracia estable o inestables, eficiente o ineficiente, adaptable o inmovilista, fácil o difícil, es la polarización; que la polarización a tener en cuenta es de tipo izquierda - derecha" (Sartori, 1992, p. 450).

Así en los testimonios encontramos lo siguiente:

"Somos mariateguistas, somos socialistas, somos marxistas... Lo que nos diferencia primero, sería los partidos que nacen en la región son algo improvisado y trabajan solo para las elecciones... Otro es que somos mariateguistas, otros no se reconocen como mariateguistas, ni socialistas, ni siquiera izquierdistas...Otro seria nuestro vínculo con las organizaciones sociales" (Dirigente, PDR).

"Básicamente este movimiento está abocado a lo que es la parte social de repente un poco ahí estar hay en el centro o izquierda” (Autoridad, FADEP).

En cuanto a la orientación ideológica, los actores políticos, en general, conocen la orientación ideológica de su organización política e identifican algunas diferencias respecto a las demás organizaciones políticas regionales. Así mismo, asumen una postura de izquierda y centro izquierda afines a los valores democráticos, humanistas y culturales.

\section{Visión de desarrollo regional}

Ley de Partidos Políticos, Ley $\mathrm{N}^{\circ}$ 28094, Art. 23일 literal A, establece como requisito indispensable para la inscripción de candidatos de cualquier organización política la presentación de un plan de gobierno. La Resolución $\mathrm{N}^{\circ}$ 272-2014-JNE, establece que la visión de desarrollo regional al conjunto de ideas generales integradas coherentemente, que expresan y proveen el marco de referencia de lo que la organización política desea lograr para el ámbito en un futuro determinado; y que éste forma parte del plan de gobierno que las organizaciones presentan al inscribirse para participar en un proceso electoral y que es de acceso público mediante el portal institucional del Jurado Nacional de Elecciones.

Respecto a la visión de desarrollo, los entrevistados afirman que:

Revista Revoluciones -33- Vol. 1, No 1 (2019), pp. 25-42 
"Nosotros planteamos que la visión que tenemos en convertir a la región de Puno en un eje articulador en el plano social, político y económico del sur del Perú... También buscamos a que esta región articule social, política y económicamente no solo al sur del Perú sino también esta parte central de América del sur, tenemos una visión de sociedad que de oportunidad a todos no y no haya exclusiones". (Líder político, PDR). "Anhelamos una región con desarrollo para todos sus ciudadanos, identificados con su cultura, integrados entre las culturas, entre pueblos, ciudades". (Autoridad, PICO). "Pensamos una región con población que haya alcanzado un nivel de bienestar, sobre la base de la diversidad intercultural, educación de calidad y el desarrollo competitivo" (Personero legal, CONFIA).

"Que... Tengamos un fortalecimiento verdadero del desarrollo humano y sostenible para la región” (Autoridad, FADEP).

En cuanto a la visión de desarrollo regional, los actores políticos, en general, coinciden en visionar el desarrollo de la región con calidad de vida para las personas, se enfatiza la identidad cultural y la integración de la región. El PDR, PICO y CONFIA visionan con identidad cultural. El PDR y PICO con descentralización e integración. El PICO con democracia y gobernabilidad. Y, finalmente, el FADEP con el desarrollo humano.

\section{Planificación y formación de líderes}

La planificación y la formación de líderes en las organizaciones políticas significan un proceso de proporcionar conocimientos, capacidades y habilidades a los elementos en formación asociadas para alcanzar objetivos organizacionales. "Los cuadros partidistas deben ser formados en actividades especiales de acuerdo a las funciones que cumplan en el interior de la organización" (Tapia, 1984, p. 42).

En cuanto a la planificación para la formación de los líderes (Figura $\mathrm{N}^{\circ}$ 04), sólo los actores políticos de la organización política PDR afirman contar con un plan, para ello; pero que no se cumple a cabalidad. Así mismo, esta actividad se realiza de manera improvisada y limitada en todas las organizaciones políticas lo que muestra que no se asume actitudes positivas que permitan la formación y competencia de liderazgos en las organizaciones políticas regionales. 


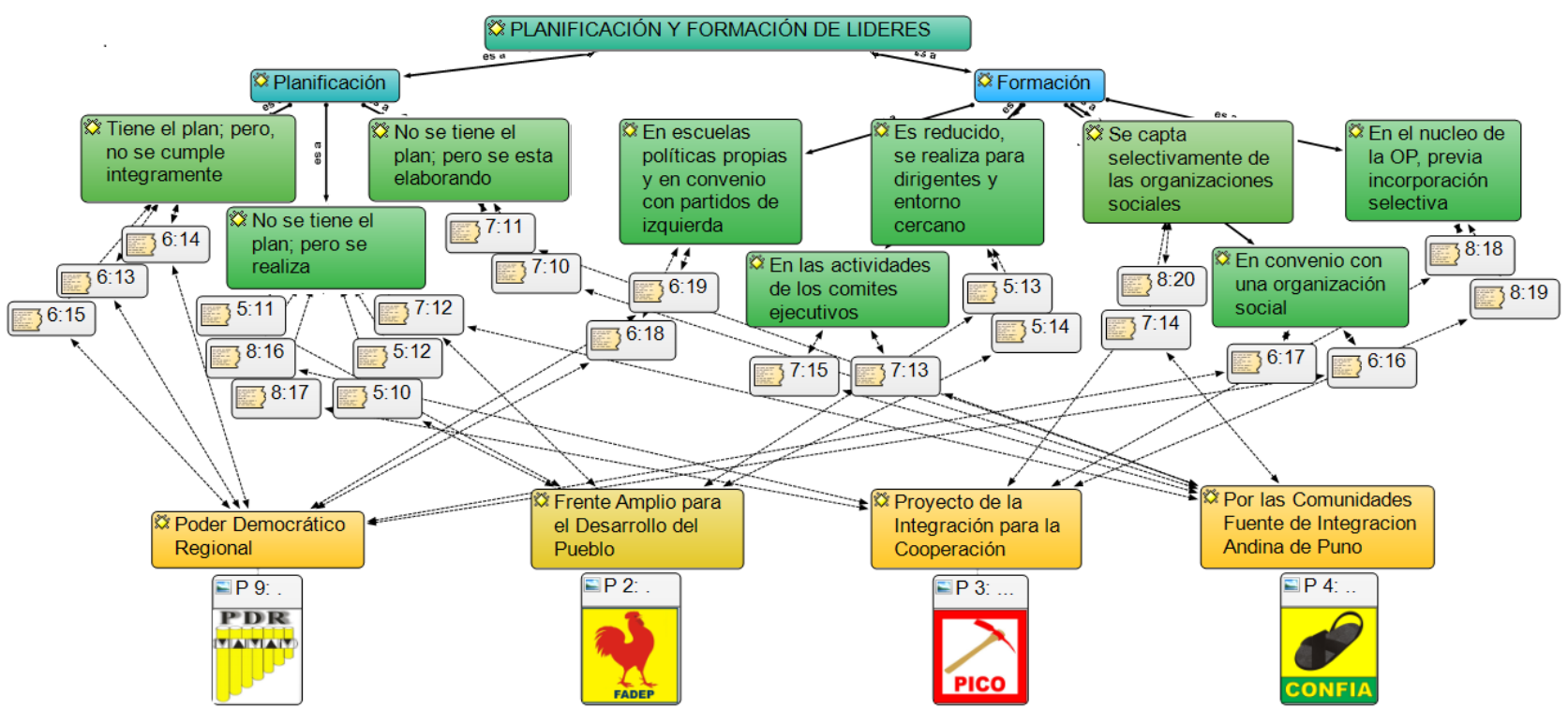

Figura 4. Red hermenéutica de actitudes sobre la planificación y formación de líderes de las organizaciones políticas regionales (ATLAS.ti7).

En relación a la planificación para la formación ideológica de los líderes, los actores políticos del FADEP, PICO y CONFIA expresan que no tienen un plan de formación ideológica de líderes, pero, en la práctica se realiza. Los del PDR refieren que tiene el plan para formar líderes, pero ésta no se cumple íntegramente. Y, finalmente, en el CONFIA manifiesta que no tiene el plan para formar líderes, pero, está en un proceso de elaboración; respecto a la formación ideológica de los líderes en su organización política, los del PDR manifiestan que ésta se realiza en escuelas políticas organizadas por sí mismos, en convenio con partidos políticos de izquierda y con una organización social. Desde el FADEP se expresa que se realiza de manera reducida solamente para los dirigentes y el entorno cercano. Mientras en el PICO, ésta se realiza en el núcleo de la organización política previa incorporación selectiva de los líderes para su formación y a través de la captación selectiva de dirigentes u otros en las organizaciones sociales. Finalmente, en el movimiento CONFIA ésta se realiza en las actividades que organizan los comités ejecutivos de la organización política.

A partir de los testimonios podemos decir que las organizaciones políticas realizan actividades poco planificadas, de manera improvisada y reducida para una élite en eventos propios de la organización política y organizaciones sociales.

\section{Militantes}

Mientras una organización exista y funcione tiene que cumplir el triple cometido de ganar miembros, lograr su permanencia en ella y hacer que desempeñen sus cometidos (Mayntz, 1990, p. 144). Las organizaciones políticas tienen esa necesidad, por un lado, para lograr los cometidos en la organización política. Desde los movimientos regionales se implementan una serie de actividades como se expresa en los siguientes testimonios: 
"Hay etapas en la formación primero se invita simpatizantes amigos a las escuelas políticas luego va pasando a otros niveles hasta su ejercicio político y como propuesta política" (Dirigente, PDR).

"Bueno, te diré que plan como tal no pero son los hechos que realizamos como organización política y sobre todo es involucrase con las organizaciones sociales apoyar sus actividades y desde ahí se va captando militantes" (Autoridad, PICO).

"Actualmente no se tiene un plan para incorporar militantes, pero es una práctica común del día a día... como militantes hacemos un contacto más personal con familiares o amigos para poder incorpóralos también" (Candidato, CONFIA).

"No tenemos un plan, pero permanentemente hacemos una actualización de padrón de afiliados al movimiento y también invitamos a la gente que quiera sumarse a este proyecto" (Ex personero legal, FADEP).

Los actores políticos, en general, afirman no contar con un plan para ello, los dirigentes, líder político y el candidato tienen actitudes alentadoras respecto a la captación de militantes y realizan actividades más formales para captar militantes en cuanto a los demás actores políticos tienen una actitud poca motivadora de captación de militantes porque realizan actividades poco formales y para el momento.

En relación a los derechos de los militantes, existe coincidencias respecto a elegir y ser elegidos para cargos dirigenciales o como candidatos a cargos públicos. El PDR y CONFIA afirman que tienen voz (opinión) y voto (capacidad de decisión) en asuntos de competencia de la organización política. Y, finalmente, el FADEP indica que tienen el derecho de exigir la rendición de cuentas de la organización política. En relación a los deberes de los militantes, los del PDR, FADEP y PICO manifiestan que deben basarse en el compromiso y lealtad a la organización política. El PDR, FADEP y CONFIA expresan que tienen que contribuir económicamente a la organización política y, finalmente, el PICO y CONFIA enfatizan que tiene que participar activamente en la organización política.

\section{Expectativas de los actores políticos sobre la participación de las organizaciones políticas regionales en un proceso electoral}

\section{Participación en un proceso electoral}

La participación de las organizaciones políticas regionales y presentación de candidatos en el ámbito de la circunscripción regional en un proceso electoral de elecciones regionales y municipales se realiza acorde a la Ley de Elecciones Regionales, Ley ${ }^{\circ} 27683$ Artículo $11^{\circ}$ sobre la inscripción de organizaciones políticas, literal 1 dispone que: "en el proceso electoral regional pueden participar las organizaciones políticas y las alianzas políticas que se constituyan con registro de inscripción vigente en el Jurado Nacional de Elecciones". Al respecto se tiene los siguientes testimonios:

Revista Revoluciones -36- Vol. 1, No 1 (2019), pp. 25-42

Esta obra está bajo una licencia internacional Creative Commons Atribución 4.0. 
"Generalmente en las anteriores contiendas hemos presentado en un $80 \%$ y $81 \%$ de las provincias y distritos nunca hemos cubierto el 100\%, desearíamos hacerlo" (Líder político, $P D R)$.

"Creo que si estamos preparados y con la experiencia de estas elecciones para la próxima estaremos en mejores condiciones... Estamos haciendo el trabajo y de seguro para el 2018 estaremos en mejores condiciones" (Personero legal, CONFIA).

"Nuestra fortaleza es que tenemos comités partidarios en la totalidad de provincias y en muy buena parte de los distritos eso nos permite poder presentar candidatos en ellos porque tenemos presencia en la región" (Autoridad, PICO).

"Políticamente considero que si... Efectivamente en un tanto por ciento, sin duda en todas queremos, una lista regional obliga a tener candidatos en las 13 provincias y en los 109 distritos" (Dirigente, FADEP).

En cuanto a la participación y cobertura d aparece el bastión electoral a partir del cual se busca ejercer el control de toda una circunscripción electoral que alberga una población electoral significativa, y que constituye una línea de protección y defensa férrea de la organización política.

\section{Candidatos en un proceso electoral}

Los candidatos en un proceso electoral, además de reunir los requisitos individuales y de lista para su inscripción, según la circunscripción electoral deben mostrar el mejor perfil, es así; "el candidato que muestra posturas claras, lealtad sin maculas, coherencia, lógica y sabe transmitirlo, tiene una mayor posibilidad de conseguir el apoyo del electorado" (Elgarresta, 2002, p. 122).

A continuación, presentamos los testimonios referidos a las candidaturas:

"Los candidatos propios del partido y la federación si están formados, hay militantes muy buenos peros eso no indica que todos van a ser candidatos" (Ex dirigente PDR). "Al decir que estamos prestos también es que tenemos el equipo humano y en su debido momento se llevara a una elección interna" (Autoridad, FADEP).

"Estamos en es a formación y en términos generales si tenemos muy buenas propuestas que actualmente están asumiendo y otros que todavía están a la espera de otro proceso electoral" (Dirigente, PICO).

"Sí, hay muchos de nuestra organización política que están y van a ejercer también cargos en esta oportunidad y otros que van ser el soporte técnico de las gestiones locales" (Personero legal, CONFIA).

En cuanto a la posibilidad de tener candidatos idóneos, tanto los dirigentes, líder, personeros legales, autoridades y el candidato tienen expectativas altas porque dicen tener políticos y profesionales con personalidad, es más, mencionan que hay gente que tiene experiencia, que ha participado y que está en formación. 


\section{Aspectos individuales y organizacionales para el éxito en un proceso electoral}

El recurso humano calificado constituido en el comité político o equipo multidisciplinario "deberá estar compuesto por personas de todas y cada una de las profesiones y sectores... deberá ser la mejor representación en calidad humana y experiencia” (Elgarresta, 2002, p. 157). Las principales funciones de este equipo es asesorar al candidato y aportar al desarrollo del programa de gobierno, la campaña y en un posible futuro gobierno en su área específica. Así mismo, la disponibilidad de los recursos económicos para la operatividad de la campaña de un proceso electoral es una prioridad la función básica, entre otras existentes "de un buen candidato... recaudar dinero para la campaña" (Elgarresta, 2002, p. 125).

"Sí, tenemos un equipo que se compone de sociólogos, abogados, antropólogos y sobre todos los dirigentes... Se financia directamente por el aporte de cada militante o de las organizaciones sociales y otros particulares" (Ex dirigente PDR).

"Tenemos un equipo profesional y también debemos de incorporar en este caso a los jóvenes...Consideramos que debemos de tener un equipo multidisciplinario... Este movimiento se auto sostiene, se autofinancia con el apoyo de los militantes de la organización política" (Autoridad, FADEP).

"Hay bastantes profesionales que integran el partido y eso nos garantiza tener un buen equipo... Tenemos los militantes comprometidos con la organización... y también están los candidatos y personas que aportan en una cantidad un poco más fuerte" (Autoridad, PICO).

"Tenemos lo que es la comisión política ese es un buen espacio para que nuestros futuros técnicos y asesores políticos se desarrollen... Los aportes de los militantes garantizan esta situación" (Candidato, CONFIA).

Respecto a la posibilidad de contar con un buen equipo técnico para un proceso electoral, se concluye que las organizaciones políticas tienen un equipo multidisciplinario y comité político conformado por profesionales de diferentes especialidades que constituyen el recurso humano calificado; en relación a la posibilidad de financiar un proceso electoral, se concluye que las organizaciones políticas cuentan con los aportes de los militantes, particulares, candidatos y en algunos casos con la recaudación de fondos en actividades. Por tanto, son expectativas favorables que contribuirán al éxito en un proceso electoral.

\section{Aspectos individuales de los candidatos}

La cualidad más importante de un candidato se centra en la capacidad de comunicación para persuadir a los electores; "la efectividad de un buen candidato es juzgada en gran parte por su habilidad de transmitir mensajes claros. Comunicadores poderosos se hacen estrellas políticas" (Elgarresta, 2002, p. 125). En cuanto a los aspectos individuales de los candidatos (Figura $\mathrm{N}^{\circ}$ 05), los actores políticos, en general, tienen expectativas altas ya que, ellos, perciben que los candidatos de sus respectivas organizaciones políticas tienen características personales favorables para ganar un proceso electoral.

Revista Revoluciones -38- Vol. 1, $\mathrm{N}^{\circ}{ }_{1}$ (2019), pp. 25-42

Esta obra está bajo una licencia internacional Creative Commons Atribución 4.0.

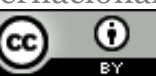




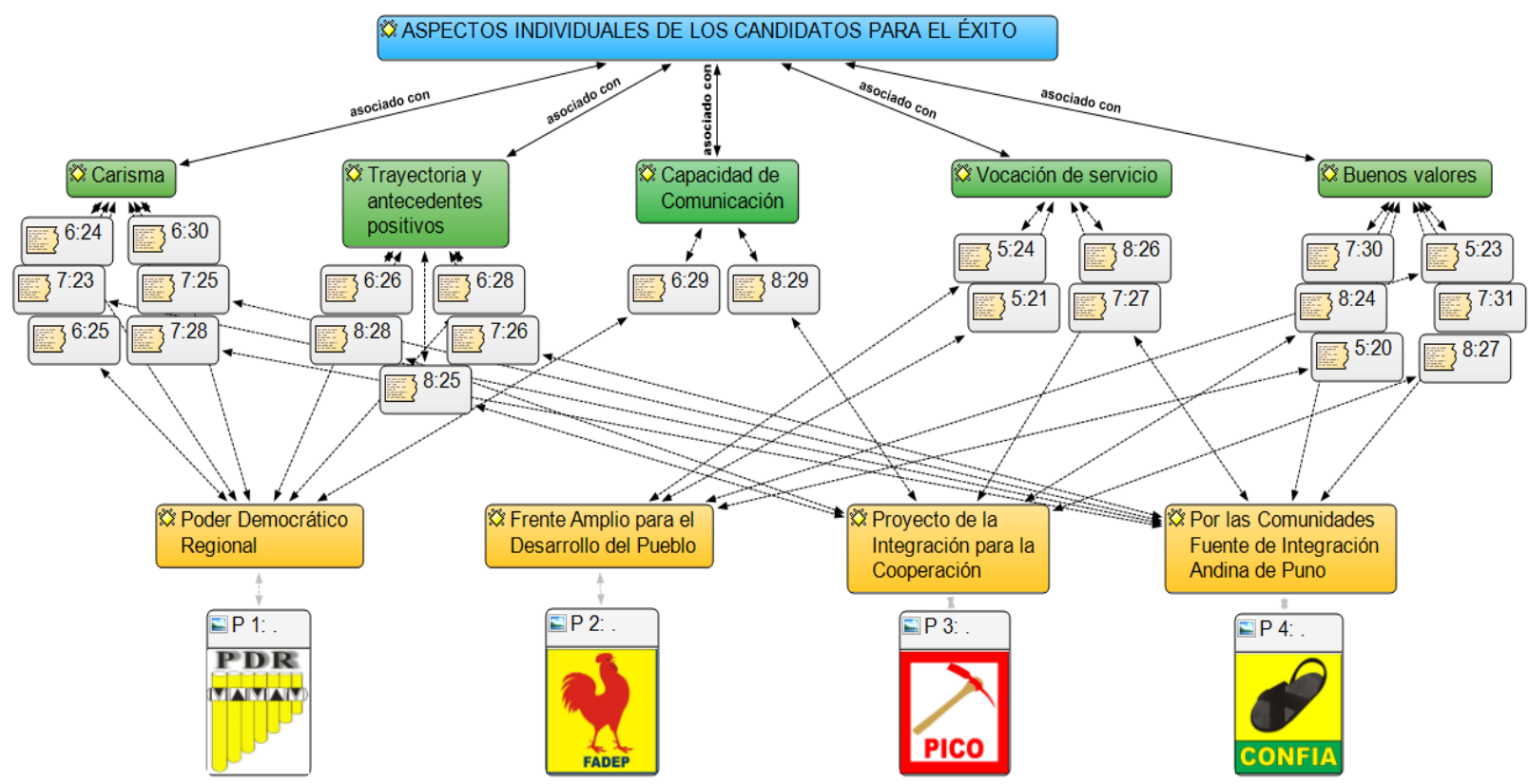

Figura 5. Red hermenéutica de expectativas sobre aspectos individuales de los candidatos para el éxito de las organizaciones políticas regionales en un proceso electoral (ATLAS.ti7).

Los aspectos individuales de los candidatos que contribuyen al éxito en un proceso electoral los actores políticos del FADEP, PICO y CONFIA manifiestan que está asociado a la vocación de servicio y los buenos valores. El PDR, PICO y CONFIA refieren que está asociado a la trayectoria y antecedentes positivos. El PDR y CONFIA manifiestan que está asociado al carisma. Y finalmente, el PDR y PICO refieren que está asociado a la capacidad de comunicación que posean y muestren los candidatos de las organizaciones políticas.

Respecto a los aspectos individuales de los candidatos, podemos afirmar que los candidatos tienen vocación de servicio, buenos valores, antecedentes positivos, carisma y son comunicativos. Por tanto, son expectativas favorables que contribuirán al éxito en un proceso electoral.

\section{Aspectos organizacionales de la organización}

En un proceso electoral, las organizaciones políticas regionales deben generar la mayor capacidad organizativa, económica e ideológica ya que de la disponibilidad y adecuada utilización de los mismos dependerá el éxito "en una democracia, una multiplicidad de fuerzas políticas compite dentro de un marco institucional. Los participantes en la competencia democrática cuentan con recursos económicos, organizativos e ideológicos desiguales" (Przeworski, 2005, p. 16).

Desde la perspectiva de los actores políticos, lograr el éxito como organizaciones políticas se debe de considerar los siguientes aspectos:

"Un buen candidato y una buena campaña" (Ex dirigente PDR). 
"Muy importante es la planificación y el diseño, digamos del plan de gobierno y también del plan de campaña" (Dirigente, FADEP).

"Sería una buena organización de los comités, operatividad de los agentes y buena estrategia de campaña” (Autoridad, PICO).

"Buena propuesta de cuadros y buena campaña" (Candidato, CONFIA).

$\mathrm{Al}$ respecto, los actores políticos tienen expectativas altas ya que perciben que la buena organización de su estructuración regional posibilitaría un éxito en un proceso electoral; sin embargo, los demás actores políticos tienen expectativas altas en base a la realización de una buena campaña electoral y la participación activa de los militantes, de manera general consideran que cada organizaciones política tiene una estructura, organización, dirección, propuesta de gobierno, preparación política, campaña electoral y conocimiento de gestión pública. Por tanto, son expectativas favorables que contribuirán al éxito en un proceso electoral.

\section{CONCLUSIONES}

Las representaciones sociales que tienen los actores políticos sobre la gestión de las organizaciones políticas regionales son adecuadas. Respecto a los conocimientos que tienen los actores políticos sobre la organización interna de las organizaciones políticas regionales estas son suficientes porque conocen la estructura funcional, identifican los principales cargos de la organización; sin embargo, desconocen las principales funciones de los cargos e identifican que la democracia interna es una forma de tomar decisiones colectivas y de gobierno participativo en el ejercicio del poder para la elección de dirigentes, candidatos y la toma de decisiones; también, conocen los documentos de gestión interna como el estatuto.

Las actitudes que adoptan los actores políticos sobre la ideología, los líderes y militantes de las organizaciones políticas regionales son positivas, asumen una orientación ideológica de izquierda y centro izquierda afines a los valores democráticos, humanistas y culturales. Tienen una visión de desarrollo regional orientado al desarrollo humano con calidad de vida e identidad cultural, descentralizado e integrado; sin embargo, asumen actitudes pasivas sobre la formación de líderes porque no tienen un plan establecido para ello, realizan actividades poco planificadas de manera improvisada y reducida para una élite; también, asumen actitudes pasivas sobre la captación de militantes hay poca vocación de militancia.

Las expectativas que tienen los actores políticos sobre la participación de las organizaciones políticas regionales en un proceso electoral son favorables porque tienen la decisión política, experiencia exitosa y autorización legal favorables para la participación; sin embargo, tienen expectativas poco favorables sobre las propuestas políticas para asumir el gobierno regional dado que hay poco liderazgo y liderazgo personalizado.

\section{REFERENCIAS BIBLIOGRÁFICAS}

Revista Revoluciones -40- Vol. 1, $N^{\circ} 1$ (2019), pp. 25-42

Esta obra está bajo una licencia internacional Creative Commons Atribución 4.0. 
Arriga, C. (2003). Historia del Perú. Arequipa - Perú. Ediciones Vibupa.

Bobbio, N. (1989). Estado, gobierno y sociedad: por una teoría general de la política. México:

Fondo de Cultura Económica.

Bobbio, N. (1982). Diccionario Político. México.

Chang, R. (s.f.) Los Sistemas Electorales.

Comisión de Plan. (2014). Plan de gobierno regional Puno 2015 - 2018. Puno. PDR. Recuperado en fecha 28 de marzo del 2015 desde: http://www.infogob.com.pe/Localidad/ubigeoprocesodetalle.aspx?IdUbigeo=200000 \&IdLocalidad $=1626 \& I d T a b=1 \& I d E l e c c i o n=120$

Comisión de Plan. (2014). Plan de gobierno regional Puno 2015 - 2018. Puno. FADEP. Recuperado en fecha 28 de marzo del 2015 desde: http://www.infogob.com.pe/Localidad/ubigeoprocesodetalle.aspx?IdUbigeo=200000 \&IdLocalidad $=1626 \& I d T a b=1 \& I d E l e c c i o n=120$

Comisión de Plan. (2014). Plan de gobierno regional Puno 2015 - 2018. Puno. PICO. Recuperado en fecha 28 de marzo del 2015 desde: http://www.infogob.com.pe/Localidad/ubigeoprocesodetalle.aspx?IdUbigeo=200000 \&IdLocalidad $=1626 \& I d T a b=1 \& I d E l e c c i o n=120$

Comisión de Plan. (2014). Plan de gobierno regional Puno 2015 - 2018. Puno. CONFIA. Recuperado en fecha 28 de marzo del 2015 desde: http://www.infogob.com.pe/Localidad/ubigeoprocesodetalle.aspx?IdUbigeo=200000 \&IdLocalidad $=1626 \& I d T a b=1 \& I d E l e c c i o n=120$

De Souza, M. (2004). El desafío del conocimiento: investigación cualitativa en salud. Argentina: Lugar editorial.

Diaz, M. A. (2011). Cultura política y Juventud: el Papel de la escuela en la formación política de los jóvenes. Tesis de doctorado, Universidad Complutense de Madrid. Retrieved from http://www.javeriana.edu.co/biblos/tesis/politica/tesis453.pdf

Durkheim, E. (1997). Las Reglas del Método Sociológico. México: Fondo de Cultura Económica.

Duverger, M. (1987). Los partidos políticos. México: Fondo de Cultura Económica. Elgarresta, M. (2002). Conocimientos prácticos para ganar elecciones. Miami: Stratego.

Freidenberg, F. (2005). Mucho ruido y pocas nueces organizaciones partidistas $y$ democracia interna en América Latina. Salamanca: Editorial Polis.

Freidenberg, F. (2006). Democracia interna: Reto ineludible de los partidos políticos. Revista de Derecho Electoral, 20-21. San José de Costa Rica: Editorial IIDH.

Freindenberg, F. (2006). La democracia de los partidos políticos en América Latina: entre la ilusión y el desencanto. San José de Costa Rica: Editorial IIDH.

Gómez, C. (2015). Sistema político y formas de gobierno. In Ciencia política: perspectiva multidisciplinaria (pp. 28-48). México: Universidad Autónoma de Nuevo León.

Gramci A. (1981). Cuadernos de la Cárcel. (Tomo 5) México: Ediciones Era. S.A. de C.V. INFOgob - Jurado Nacional de Elecciones (2012). Mapa Político Electoral del Perú. (Tomo 1). Lima: Jurado Nacional de Elecciones.

INFOgob - Jurado Nacional de Elecciones ROP (2013). Informe de verificación de la 
existencia y funcionamiento del domicilio legal y comités partidarios de los partidos políticos y movimientos regionales inscritos en el registro de organizaciones políticas. Lima. Jurado Nacional de Elecciones.

INFOgob - Jurado Nacional de Elecciones ROP (2013). Portal virtual Perú. Jurado Nacional de Elecciones.

Jodelet, D. (1986). La representación social: Fenómenos, conceptos y teoría. España: Ediciones Paidós.

Lee, B. (1999). El principio del poder: la influencia del honor en las empresas. México: Editorial Grijajbo S.A de C.V.

Martínez, G. (2005). Poder y organización regional al interior del PRI: Conflicto en la selección de candidatos a los gobiernos estatales, casos Nayarit y Estado de México. Mexico: Flacso.

Mayntz, R. (1990). Sociología de la Organización. Madrid: Alianza Editorial.

Meléndez, C. (Comp.). (2011). Anti - candidatos: guía analítica para unas elecciones sin partidos. Perú: Aerolíneas Editoriales S.A.C.

Meléndez, J. (2002). Guía para la Gerencia Política. Washington: Instituto Nacional Demócrata.

Mora, M. (2002). La teoría de las representaciones sociales de Serge Moscovici. México: Guadalajara.

Moscovici, S. (1979). El Psicoanálisis, su imagen y su público. Buenos Aires: Editorial Huemul.

Nohlen, D. (1999). Sistema de Gobierno, Sistema Electoral y Sistema de Partidos Políticos. México: Fundación Friedrich Naumann.

Onikov, L. \& Shishlin, N. (1983). Breve diccionario político. Moscú: Editorial Progreso.

Pachano, S. (2007). Partidos y sistema de partidos en el Ecuador. In La política por dentro: Cambios y continuidades en las organizaciones políticas de los países andinos (pp. 161212). Perú: International Institute for Democracy and Electoral Assistance; Asociación Civil Transparencia.

Parsons, T. (1976). El sistema social. Madrid: Editorial revista de occidente S.A.

Perera, M. (2005). A propósito de las Representaciones Sociales. Apuntes Teóricos, Trayectoria y Actualidad.

Pinto, J. (2003). Introducción a la Ciencia Política. Buenos Aires: Eudeba.

Pratt, H. (1987). Diccionario Sociológico. México: Fondo de Cultura Económica, S.A. de C.V. Przeworski, A. (2003). Democracia y Mercado. Buenos Aires Argentina: Editorial Akal.

Ragas, J. F. (2003). Ciudadanía, cultura política y representación en el Perú: La campaña electoral de 1850. Tesis de licenciatura, Pontificia Universidad Católica del Perú. Retrieved from http://tesis.pucp.edu.pe/repositorio/handle/123456789/5828

República de Bolivia (2009). Constitución Política del Estado Plurinacional. Bolivia.

Ruiz L. (2003). Coherencia partidista: la estructuración interna de los partidos políticos en América Latina. Madrid: Alianza Editorial.

Sartori, G. (1992). Partidos y sistemas de partidos. Madrid: Alianza Editorial.

Sartori, G. (2003). ¿Qué es la Democracia?. Buenos Aires: Editorial Taurus.

Suárez, E. (2000). Filosofía, teoría y ciencia política. In Estudios Políticos (Núm. 23, pp. 
223-233). México: Universidad Nacional Autónoma de México.

Schmitt, C. (2009). El concepto de lo político (9na. ed.). Madrid: Alianza Editorial SA.

Tanaka, M. (1999). Los partidos políticos en el Perú, 1992-1999: estatalidad, sobrevivencia y política mediática. Perú: IEP/JCAS.

Tanaka, M. (2002). La dinámica de los actores regionales y el proceso de descentralización: ¿el despertar del letargo?. Perú: IEP/JCAS.

Tapia, E. (1984). Capacitación política y formación de cuadros. Argentina: Nueva Sociedad. Tuesta, F. (2001). Sistema de partidos políticos en el Perú 1978 - 1995. Perú.

Vargas, S. (2014). Desafección política en América Latina Cultura y eficacia política. Tesis de licenciatura. Universidad de Chile. Retrieved from http://repositorio.uchile.cl/bitstream/handle/2250/131619/Tesis Salvador Vargas 070114 \%5Bfinal\%5D.pdf?sequence $=1$

Vallés, J. M. (2007). Ciencia política: Una introducción (6ta.ed.). Barcelona: Editorial Ariel. Weber, M. (1984). Ética y sociedad. Ediciones elaleph.com.

Weber, M. (2000). Política y ciencia. Ediciones elaleph.com. 